\title{
PENGARUH BEBAN KERJA TERHADAP KINERJA KARYAWAN DI LINGKUNGAN INSITUT AGAMA ISLAM NEGERI PALANGKA RAYA
}

\author{
Muhammad Riza hafizi ${ }^{1}$, \\ Institut Agama islam negeri Palangka Raya \\ Jalan G. Obos Komplek Islamic Centre Palangka Raya Kalimanatan Tengah \\ riza.hafizi@iain-palangkaraya.ac.id
}

\begin{abstract}
This study aims to analyze the effect of workload on employee performance within the State Islamic Institute of Palangka Raya. Performance is a description of the level of achievement of the implementation of a program of activities or policies in realizing the goals, objectives, vision, and mission of the organization as outlined through an organization's strategic planning. This research was conducted on 92 employees who work in IAIN Palangka Raya. The research findings indicate that the workload variable has a positive effect on employee performance in the State Islamic Institute of Palangka Raya. This is evidenced by the results of the regression test statistics obtained a value of $(\beta) 0.778(p>0.05 ; p=0.000)$. With an $R$ square adjust the value of $34 \%$. then this study successfully demonstrated that workload has a positive and significant influence on performance. Hypothesis testing uses the help of the Statistical Package for the Social Sciences program.
\end{abstract}

Keywords: Workload, performance, Palangka Raya

\begin{abstract}
Abstrak
Penelitian ini bertujuan untuk menganalisis pengaruh beban kerja terhadap kinerja karyawan di lingkungan Insitut Agama Islam Negeri Palangka Raya. Kinerja merupakan gambaran mengenai tingkat pencapaian pelaksanaan suatu program kegiatan atau kebijakan dalam mewujudkan sasaran, tujuan, visi, dan misi organisasi yang dituangkan melalui perencanaan strategi suatu organisasi. Penelitian ini dilakukan pada 92 karyawan yang bekerja di lingkungan IAIN Palangka Raya. Hasil temuan penelitian menunjukkan bahwa variabel beban kerja berpengaruh positif terhadap kinerja karyawan di Lingkungan Institut Agama Islam Negeri Palangka Raya. Hal ini dibuktikan dengan hasil statistik uji regresi diperoleh nilai sebesar sebesar $(\beta) 0.778$ ( $p>0.05 ; p=0,000$ ). Dengan nilai adjust R square sebesar $34 \%$. maka penelitian ini berhasil menunjukkan bahwa beban kerja memiliki pengaruh posititf dan signifikan terhadap kinerja. Pengujian hipotesis menggunakan bantuan program Statistical Package for the Social Sciences.
\end{abstract}

Kata Kunci: Beban kerja, kinerja, Palangka Raya 


\section{PENDAHULUAN}

Pada era modern saat ini organisasi dituntut untuk menciptakan kinerja karyawan yang kompetitif dalam mengembangkan organisasi serta mencapai tujuan-tujuannya. organisasi harus mampu membangun dan meningkatkan kinerja di dalam lingkungannya. Kinerja atau performance merupakan gambaran mengenai pencapaian terhadap pelaksanaan suatu program kegiatan atau kebijakan dalam mewujudkan sasaran, tujuan, visi, dan misi organisasi yang dituangkan melalui perencanaan strategi suatu organisasi, dan salah satu faktor yang memengaruhi tingkat keberhasilan suatu organisasi adalah kinerja karyawannya. Kinerja karyawan merupakan suatu tindakan yang dilakukan oleh karyawan dalam melaksanakan pekerjaan yang diberikan perusahaan. Setiap perusahaan selalu mengharapkan karyawannya mempunyai prestasi, karena dengan memiliki karyawan yang berprestasi akan memberikan sumbangan yang optimal bagi perusahaan.

Salah satu faktor yang mempengaruhi kinerja karyawan adalah beban kerja, beban kerja seseorang sudah ditentukan dalam bentuk standar kerja perusahaan menurut jenis pekerjaannya. Beban kerja karyawan dapat terjadi dalam tiga kondisi. Pertama, beban kerja sesuai standar. Kedua, beban kerja yang terlalu tinggi (over capacity). Ketiga, beban kerja yang terlalu rendah (under capacity). Beban kerja yang terlalu berat atau ringan akan berdampak terjadinya inefisiensi kerja. Beban kerja yang terlalu ringan berarti terjadi kelebihan tenaga kerja, kelebihan ini menyebabkan organisasi harus menggaji jumlah karyawan lebih banyak dengan produktivitas yang sama sehingga terjadi inefisiensi biaya. Sebaliknya, jika terjadi kekurangan tenaga kerja atau banyaknya pekerjaan dengan jumlah karyawan yang dipekerjakan sedikit, dapat menyebabkan keletihan fisik maupun psikologis bagi karyawan. Akhirnya karyawan pun tidak produktif karena terlalu lelah

Institut Agama Islam Negeri (IAIN) Palangka Raya merupakan Institut Agama Islam Negeri terbesar di Kalimantan Tengah yang telah terakreditasi B dari Badan Akreditasi Nasional. IAIN Palangka Raya terdiri dari Strata 1 dan Strata 2, Starata 1 terdiri dari 17 program studi yang terbagi kedalam empat fakultas yaitu Fakultas Tarbiah, Fakultas Syariah, Fakultas Ushuluddin dan Dakwah serta Fakultas Ekonomi dan Bisnis Islam, sedangkan Strata 2 mempunyai 4 program studi yaitu Program Studi Magister Ekonomi Syariah, Program Studi Hukum Keluarga, Program Studi Pendidikan Islam dan Program Studi Pendidikan Agama Islam. IAIN Palangka Raya memiliki standar pelayanan yang baik serta didukung dengan sarana dan prasarana yang mumpuni guna mencapai visi, misi dan tujuan dari IAIN Palangka Raya yaitu Tahun 2023 Menjadi Universitas Islam Negeri Terdepan, Unggul, Terpercaya dan Berkarakter. IAIN Palangka Raya bertanggungjawab penuh dalam menyelenggarakan pelayanan terhadap stakeholder. Oleh sebab itu, civitas akademika di lingkungan IAIN 
Palangka Raya harus memiliki kinerja yang baik dan profesional agar dapat membantu Insititusi mendapatkan kepercayaan dari stakeholder sehingga visi dan misi dapat terwujud.

Tabel 1.1 Jumlah Mahasiswa Baru IAIN Palangka Raya

MAHASISWA BARU IAIN PALANGKA RAYA

PERIODE 2016-2018

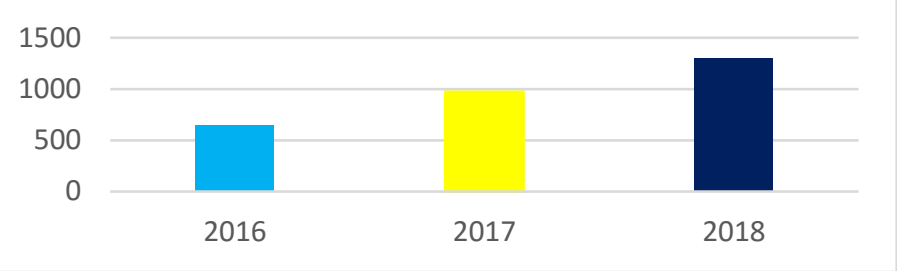

Tingginya kepercayaan stakeholders kepada IAIN Palangka Raya, hal tersebut direspon dengan cepat oleh pimpinan IAIN Palangka Raya berserta jajarannya menginstruksikan kepada para civitas akademika IAIN Palangka Raya untuk memberikan pelayanan yang terbaik dari segi sarana dan prasarana yang mumpuni maupun transfer pengetahuan yang berbasis dengan teknologi. Dengan meningkatnya jumlah mahasiswa, maka meningkat pula pelayanan yang harus dilakukan kepada stakeholder. Permasalahan yang sering dialami oleh tenaga pengajar adalah beban kerja yang berlebihan karena mereka tidak hanya memberikan pelayanan terbaik kepada stakeholder juga wajib untuk melakukan tridarma perguruan tinggi yaitu mengajar, meneliti dan pengabdi kepada masyarakat serta sebagian menduduki jabatan struktural di lingkungan IAIN Palangka Raya. Hal tersebut dikarenakan keterbatan sumber daya yang dimiliki oleh IAIN Palangka Raya sehingga ada sebagian tenaga pengajar yang merangkap tugas dan jabatan.

Tingginya tuntutan beban kerja, keterbatasan waktu yang dimiliki oleh tenaga pengajar di IAIN Palangka Raya, hal ini memungkinkan sebagian karyawan akan mengalami penurunan kinerjanya, dengan lingkungan kerja yang baik dalam arti hubungan harmonis dengan atasan maupun hubungan sesama rekan kerja ataupun hubungan dengan bawahan diharapkan kelebihan beban kerja tersebut tidak menurunkan kinerja. Berdasarkan latar belakang tersebut peneliti tertarik untuk meneliti mengenai "Pengaruh Beban Kerja terhadap Kinerja Karyawan di Lingkungan Insitut Agama Islam Negeri Palangka Raya”.

\section{TINJAUAN TEORITIK/ LITERATURE REVIEW}

\subsection{Beban Kerja}

Salah satu aspek yang mempengaruhi kinerja karyawan pada sebuah perusahaan adalah beban kerja oleh karena itu beban kerja merupakan salah satu variabel penting dalam meningkatkan untuk kinerja karyawan. Menurut Permendagri Nomor 12 tahun 2008, beban 


\section{2 |Pengaruh Beban Kerja Terhadap Kinerja di Lingkungan IAIN Palangka Raya}

kerja adalah besaran pekerjaan yang harus dipikul oleh suatu jabatan/unit organisasi dan merupakan hasil kali antara volume kerja dan norma waktu. Menurut beban kerja adalah yang terlalu banyak dapat menyebabkan ketegangan dalam diri seseorang sehingga menimbulkan stres. Hal ini bisa disebabkan oleh tingkat keahlian yang dituntut terlalu tinggi, kecepatan kerja mungkin terlalu tinggi, volume kerja mungkin terlalu banyak dan sebagainya.

Beberapa faktor-faktor yang mempengaruhi beban kerja, yaitu:

a. Time pressure (tekanan waktu)

Secara umum dalam hal tertentu waktu akhir (deadline) justru dapat meningkatkan motivasi dan menghasilkan prestasi kerja yang tinggi, namun desakan waktu juga dapat menjadi beban kerja berlebihan kuantitatif ketika hal ini mengakibatkan munculnya banyak kesalahan atau kondisi kesehatan seseorang berkurang.

b. Jadwal kerja atau jam kerja.

Jumlah waktu untuk melakukan kerja berkontribusi terhadap pengalaman akan tuntutan kerja, yang merupakan salah satu faktor penyebab stres di lingkungan kerja. Hal ini berhubungan dengan penyesuaian waktu antara pekerjaan dan keluarga terutama jika pasangan suami-istri sama-sama bekerja. Jadwal kerja strandart adalah 8 jam sehari selama seminggu. Untuk jadwal kerja ada tiga tipe, yaitu: night shift, long shift, flexible work schedule. Dari ketiga tipe jadwal kerja tersebut, long shift dan night shift dapat berpengaruh terhadap kesehatan tubuh seseorang.

c. Role ambiguity dan role conflict

Role ambiguity atau kemenduaan peran dan role conflict atau konflik peran dapat mempengaruhi persepsi seseorang terhadap beban kerjanya. Hal ini dapat sebagai hal yang mengancam atau menantang.

d. Kebisingan,

Kebisingan dapat mempengaruhi pekerja dalam kinerjanya. Pekerja yang kondisi kerjanya sangat bising dapat mempengaruhi efektifitas kerjanya dalam menyelesaikan tugasnya, dimana dapat mengganngu konsentrasi dan otomatis mengganggu pencapaian tugas sehingga dapat dipastikan semakin memperberat beban kerjanya

e. Informatian overload

Banyaknya informasi yang masuk dan diserap pekerja dalam waktu yang bersamaan dapat menyebabkan beban kerja semakin berat. Kemajemukan teknologi dan penggunaan fasilitas kerja yang serba canggih membutuhkan adaptasi tersendiri dari pekerja. Semakin komplek informasi yang diterima, dimana masing-masing menuntut konsekuensi yang berbeda dapat mempengaruhi proses pembelajaran pekerja dan efek lanjutannya bagikesehatan jika tidak tertangani dengan baik.

f. Temperature extremes atau heat overload. 
Sama halnya dengan kebisingan, faktor kondisi kerja yang beresiko seperti tingginya temperatur dalam ruangan juga berdampak pada kesehatan. Hal ini utamanya jika kondisi tersebut berlangsung lama dan tidak ada peralatan pengamannya.

g. Repetitive action

Banyaknya pekerjaan yang membutuhkan aksi tubuh secara berulang, seperti pekerja yang menggunakan komputer dan menghabiskan sebagian besar waktunya dengan mengetik, atau pekerja assembly line yang harus mengoperasikan mesin dengan prosedur yang sama setiap waktu atau dimana banyak terjadi pengulangan gerak akan timbul rasa bosan, rasa monoton yang pada akhirnya dapat menghasilkan berkurangnya perhatian dan secara potensial membahayakan jika tenaga gagal untuk bertindak tepat dalan keadaan darurat. Aspek ergonomi dalam lay out tempat kerja.

h. Tanggung jawab

Setiap jenis tanggung jawab (responsibility) dapat merupakan beban kerja bagi sebagian orang. Jenis-jenis tanggung jawab yang berbeda, berbeda pula fungsinya sebagai penekan. Hasil penelitian menunjukkan bahwa tanggung jawab terhadap orang menimbulkan tekanan yang berhubungan dengan pekerjaan. Sebaliknya semakin banyak tanggung jawab terhadap barang, semakin rendah indikator tekanan yang berhubungan dengan pekerjaan.

\subsection{Kinerja Karyawan}

Kinerja adalah hasil kerja secara kualitas dan kuantitas yang dicapai oleh seorang pegawai dalam melaksanakan tugasnya sesuai denga tanggung jawab yang diberikan kepadanya. Kinerja seringkali dipikirkan sebagai pencapaian tugas, dimana istilah tugas sendiri berasal dari pemikiran aktivitas yang dibutuhkan oleh pekerja. Karena kinerja pegawai merupakan suatu tindakan yang dilakukan karyawan dalam melaksanakan pekerjaan yang dilakukan perusahaan. Menurut Anwar Prabu Mangkunegara dalam bukunya Manajemen Sumber Daya Manusia Perusahaan, mengemukakan pengertian kinerja adalah hasil kerja secara kualitas dan kuantitas yang dicapai oleh seorang karyawan dalam melaksanakan tugasnya sesuai dengan tanggung jawab yang diberikannya.

\section{Indikator-Indikator Kinerja Karyawan}

Kriteria Bernandin dan russell sebagaimana dikutip oleh Gomes merupakan kriteria yang akan penulis jadikan indikator pengukuran kinerja pegawai dalam penelitian ini yang bahwa indikator pengukuran kinerja pegawai adalah sebagai berikut:

a) Quantity of work: jumlah kerja yang dilakukan dalam suatu periode yang ditentukan. 
b) Quality of work: kualitas kerja yang dicapai berdasarkan syarat-syarat kesesuaian dan kesiapanya.

c) Job Knowledge: luasnya pengetahuan mengenai pekerjaan dan keterlampilannya.

d) Creativeness: keaslian gagasan-gagasan yang dimunculkan dan tindakan-tindakan untuk menyelesaikan persoalan-persoalan yang timbul.

e) Cooperation: kesediaan untuk bekerjasama dengan orang lain atau sesama manusia.

f) Dependability: kesadaraan untuk dapat dipercaya dalam hal kehadiran dan penyelesaian kerja.

g) Intiative: semangat untuk melaksanakan tugas-tugas baru dan dalam memperbesar tanggung jawabnya.

h) Personal Qualities: menyangkut kepribadian, kepemimpinan, keramahtamahan dan integritas pribadi.

\subsection{Pengembangan Hipotesis}

Menurut Kahneman dalam Warr Salah satu penyebab menurunnya performa dari beban kerja adalah keharusan untuk mengambil dua atau lebih tugas tugas yang harus dikerjakan secara bersamaan. Semakin banyaknya permintaan untuk melaksanakan tugastugas tersebut maka semakin berkurangnya performa dalam bekerja. Karyawan sering kali dihadapkan pada keharusan untuk menyelesaikan dua atau lebih tugas yang harus dikerjakan secara bersamaan. Tugas-tugas tersebut tentunya membutuhkan waktu, tenaga, dan sumber daya lainnya untuk penyelesaiannya. Adanya beban dengan penyediaan sumber daya yang sering kali terbatas tentunya akan menyebabkan kinerja karyawan menurun, masalah yang bias muncul diantaranya daya tahan karyawan melemah dan perasaan tertekan. Perasaan tertekan menjadikan seseorang tidak rasional, cemas, tegang, tidak dapat memusatkan perhatian pada pekerjaan dan gagal untuk menikmati perasaan gembira atau puas terhadap pekerjaan yang dilakukan. Hal ini akan menghalangi seseorang mewujudkan sifat positifnya, seperti mencintai pekerjaan.

Seseorang yang meyakini serta merasa bahwa tugas yang diberikan adalah sebagai tantangan yang harus dipecahkan meskipun tugas tersebut terlalu berlebihan maka seseorang tersebut dapat tetap merasa senang terhadap pekerjaannya. Sebaliknya jika tugas yang berlebihan tersebut diyakini dan dirasakan sebagai sebuah beban maka lambat laun mereka akan mengalami kelelahan baik kelelahan fisik maupun mental sehingga dapat menurunkan kinerja.

H1: Beban Kerja Berpengaruh Terhadap Kinerja 


\section{METODE PENELITIAN/METHODS}

\subsection{Desain Penelitian}

Desain penelitian yang dilakukan dalam penelitian ini menggunakan teknik penelitian kuantitatif. Penelitian dilakukan dengan cara mengumpulkan dan mengolah data primer yang berasal dari jawaban responden melalui penyebaran kuesioner dan kemudian menginterpretasikan hasil penelitian tersebut.

\subsection{Data dan Pengumpulan Data}

Penelitian ini menggunakan data primer. Data primer merupakan data penelitian yang diperoleh dari responden secara langsung. Alat pengumpulan data yang digunakan dalam penelitian ini adalah kuesioner. Metode pengumpulan data yang dilakukan adalah survei, menggunakan survei yang dikelola sendiri dengan menyebarkan kuesioner secara langsung maupun online kepada responden dan diisi sendiri oleh responden

\subsection{Sampel dan Teknik Pengambilan Sampel}

Kriteria sampel yang digunakan dalam penelitian ini adalah tenaga pengajar di lingkungan Institut Agama Islam Negeri Palangka Raya yang telah bergabung dalam selama lebih kurang 1 tahun. Hal ini didasari karena karyawan yang telah lama bergabung lebih memahami karakteristik kerjanya, pemimpin, maupun rekan kerjanya. Metode pengambilan sampel menggunakan nonprobability sampling. Teknik pengambilan sampel yang digunakan adalah purposive sampling. Purposive sampling digunakan karena sampel memiliki kriteriakriteria tertentu yang diisyaratkan.

\subsection{Uji Instrumen}

Pengujian instrumen dilakukan untuk menguji apakah instrumen yang digunakan mampu mengukur konstruk penelitian yang ingin diukur, tahapan ini meliputi uji validitas dan reliabilitas.

Uji validitas digunakan untuk menguji apakah alat ukur atau instrument yang digunakan mampu mengukur apa yang ingin diukur. Validitas konstruk digambarkan dengan menggunakan confirmatory factor analysis. Pengujian validitas konstruk dilakukan untuk melihat apakah item-item pernyataan yang digunakan benar-benar mempresentasikan konstruk laten yang diukur.

Reliabilitas berkaitan dengan akurasi dari sebuah prosedur pengukur. Reliabilitas dianggap baik jika beberapa indicator yang berbeda dapat mengukur konstruk yang sama dan memberikan hasil yang berbeda. Reliabilitas berkaitan dengan konsistensi variable indikator dalam mengukur konstruknya. Reliabilitas dalam penelitian ini menggunakan construct 
126 |Pengaruh Beban Kerja Terhadap Kinerja di Lingkungan IAIN Palangka

Raya

reliability. Construct reliability yang baik, jika nilai construct reliability $\geq 0,70$ dan nilai variance extracted $\geq 0,50$

\subsection{Analisis Data}

Analisis data dan interpretasi ditujukan untuk menjawab pertanyaan-pertanyaan penelitian untuk mengungkap fenomena tertentu. Analisis data merupakan proses penyederhanaan data ke dalam bentuk yang lebih mudah dibaca dan diimplementasikan. Analisis data penelitian ini menggunakan Sofware SPSS. Dengan model persamaan sebagai berikut:

$$
\mathrm{Y}=\beta_{\mathrm{o}}+\beta_{1} \mathrm{X}_{1}+\mathrm{e}_{\mathrm{i}}
$$

Dimana $Y$ : variabel dependen yaitu kinerja , $\beta$ : koefisien, $X$ : variabel independen yaitu beban kerja, dan $e:$ error

\section{Deskripsi Responden}

Karateristik responden pada penelitian ini meliputi jenis kelamin, usia responden dan pendidikan terakhir. Dari 150 kuesioner yang dibagikan dosen dan tenaga pendidik. Secara keseluruhan peneliti mendapatkan respon dari dosen pria sebanyak 57 (62\%) dan wanita sebanyak 35 (38\%). Usia responden, tingkat pendidikan dan data deskriptif lainnya juga didapatkan bervariasi. Hasil persentase secara keseluruhan karateristik responden tersebut dapat dicermati pada Tabel dibawah.

\begin{tabular}{|c|l|c|c|}
\hline No & \multicolumn{1}{|c|}{ Karakteristik } & Karyawan & Persentase (\%) \\
\hline 1 & Jenis kelamin & & \\
& a. Pria & 57 & $62 \%$ \\
& b. Wanita & 35 & $38 \%$ \\
\hline 2 & Usia responden & 61 & \\
& a. 25 - 33 Tahun & 17 & $66,3 \%$ \\
& b. 34-41 Tahun & 14 & $18,5 \%$ \\
& c. > 42 Tahun & & $15,2 \%$ \\
\hline 3 & Pendidikan terakhir & 66 & $71,7 \%$ \\
& a. S1 & 23 & $25 \%$ \\
& b. S2 & 3 & $3.3 \%$ \\
& c. S3 & \multicolumn{2}{|l}{} \\
\end{tabular}

Sumber diolah peneliti 


\section{HASIL DAN PEMBAHASAN}

\section{Uji asumsi klasik}

Sebelum melakukan uji hipotesis perlu dilakukan uji asumsi klasik terlebih dahulu agar penelitian tidak bias dan untuk menguji kesalahan model regresi yang digunakan dalam penelitian.menurut ghozali 2011;103), model regresi yang digunakan akan menunjukkan hubungan yang signifikan dan representatif (BLUE = Best Linier Unbiased Estimator) apabila memenuhi asumsi dasar klasik regresi yaitu apabila tidak terjadi gejala.

\section{Uji normalitas data}

Menurut Santosa dan Ashari (2005;46), pengujian normalitas adalah pengujian tentang kenormalan distribusi data Dalam penelitian ini, menggunakan Uji Kolmogrovsmirnov.

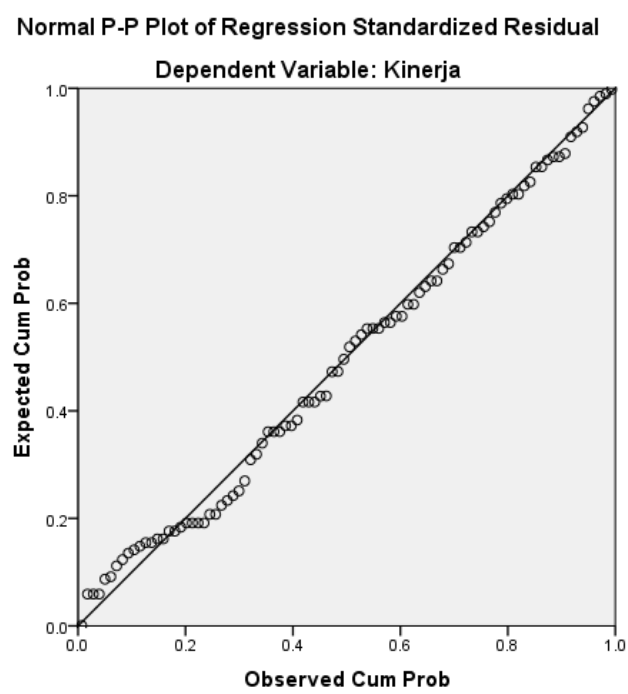

\section{One-Sample Kolmogorov-Smirnov Test}

\begin{tabular}{llr} 
& & Unstandardized Residual \\
\hline Normal Parameters & & 92 \\
\hline & Mean & .0000000 \\
\cline { 2 - 3 } Most Extreme Differences & Std. Deviation & 3.84641269 \\
\cline { 2 - 3 } & Absolute & .055 \\
\cline { 2 - 3 } & Positive & .055 \\
\cline { 2 - 3 } & Negative & -.047 \\
\hline Test Statistic & & .055 \\
\hline Asymp. Sig. (2-tailed) & & $.200^{\mathrm{c}, \mathrm{d}}$ \\
\hline
\end{tabular}
a. Test distribution is Normal.
b. Calculated from data. 
c. Lilliefors Significance Correction.

\section{Analisis Regresi}

Model Summary

\begin{tabular}{lc|r|r|r}
\hline Model & R & R Square & $\begin{array}{c}\text { Adjusted R } \\
\text { Square }\end{array}$ & $\begin{array}{l}\text { Std. Error of } \\
\text { the Estimate }\end{array}$ \\
\hline 1 & $.591^{\mathrm{a}}$ & .350 & .342 & 3.86772 \\
\hline
\end{tabular}

a. Predictors: (Constant), Beban_kerja

\begin{tabular}{|c|c|c|c|c|c|c|}
\hline \multicolumn{7}{|c|}{ ANOVAa } \\
\hline Model & & $\begin{array}{l}\text { Sum of } \\
\text { Squares }\end{array}$ & $\mathrm{df}$ & $\begin{array}{c}\text { Mean } \\
\text { Square }\end{array}$ & $\mathrm{F}$ & Sig. \\
\hline \multirow[t]{3}{*}{1} & Regression & 723.785 & 1 & 723.785 & 48.384 & $.000^{b}$ \\
\hline & Residual & 1346.335 & 90 & 14.959 & & \\
\hline & Total & 2070.120 & 91 & & & \\
\hline
\end{tabular}

a. Dependent Variable: Kinerja

b. Predictors: (Constant), Beban_kerja

\section{Coefficients $^{\mathbf{a}}$}

\begin{tabular}{|c|c|c|c|c|c|c|}
\hline \multirow{2}{*}{\multicolumn{2}{|c|}{ Model }} & \multicolumn{2}{|c|}{$\begin{array}{l}\text { Unstandardized } \\
\text { Coefficients }\end{array}$} & \multirow{2}{*}{$\begin{array}{c}\text { Standardized } \\
\text { Coefficients } \\
\text { Beta } \\
\end{array}$} & \multirow[b]{2}{*}{$\mathrm{t}$} & \multirow[b]{2}{*}{ Sig. } \\
\hline & & $\mathrm{B}$ & Std. Error & & & \\
\hline \multirow[t]{2}{*}{1} & (Constant) & 16.691 & 3.504 & & 4.763 & .000 \\
\hline & $\begin{array}{l}\text { Beban_kerj } \\
\text { a }\end{array}$ & .778 & .112 & .591 & 6.956 & .000 \\
\hline
\end{tabular}

a. Dependent Variable: Kinerja

\section{Pengujian Hipotesis}

Pengujian hipotesis dilakukan untuk menguji hipotesis yang diajukan. Hipotesis yang diajukan dalam penelitian ini terkait variable beban kerja terhadap Kinerja Karyawan. Analisis regresi sederhana dipilih untuk menganalisis pengajuan hipotesis dalam penelitian ini. Berikut ini hasil analisis regresi berganda yang dilakukan dengan menggunakan program SPSS 24 for Windows. Dari hasil analisis data regresi data diatas bahwa beban kerja berpengaruh positif terhadap kinerja karyawan di lingkungan Insititut Agama Islam Negeri Palangka Raya, hal tersebut ditunjukkan dengan nilai signifikansi kurang dari 5\%. Besarnya pengaruh Beban kerja terhadap kinerja sebesar 34\% hal tersebut dapat dilihat dari nilai Adjusted R Square. Hal itu menunjukkan bahwa variable beban kerja dapat menjelaskan kinerja sebesar $34 \%$.

\section{Pembahasan}


Hasil dari penelitian ini adalah beban kerja berpengaruh positif terhadap kinerja. Ringkasan hasil analisis regresi dengan menggunakan progam SPSS 24 for Windows dalam penelitian ini dapat dilihat pada Tabel dibawah. Berdasarkan ringkasan analisis regresi pada Tabel dibawah, diketahui bahwa beban kerja berpengaruh positif dan signifikan terhadap kinerja karyawan sebesar $(\beta) 0.778$ ( $p>0.05 ; p=0,000)$. Dengan nilai adjust $R$ square sebesar 34\%. maka penelitian ini berhasil menunjukkan bahwa beban kerja memiliki pengaruh positif dan signifikan terhadap kinerja. Bertambahnya target yang harus dicapai sebuah institusi maka, bertambah pula beban kerja pada karyawannya, Beban kerja merupakan salah satu unsur yang harus diperhatikan bagi seorang tenaga kerja untuk mendapatkan keserasian dan produktivitas. Beban kerja yang seimbang akan meningkatkan kinerja karyawan sehingga karywan di lingkungan IAIN Palangka Raya mendapatkan hasil kinerja yang efektif dan efesien.

Kinerja karyawan akan maksimal apabila indikator beban kerja terpenuhi secara seimbang seperti target yang harus dicapai, kondisi pekerjaan dan standart pekerjaan. Taget pekerjaan yang ditetapkan oleh Institutsi harus sesuai dengan kemampuan karyawan dan kapasistas yang ada pada Institusi IAIN Palangka raya. Kondisi pekerjaan yang mencakup tentang bagaimana pandangan yang dimiliki oleh individu mengenai kondisi pekerjaannya yang ada di Lingkungan IAIN Palangka Raya, mislanya mengatasi kejadian yang tak terduga seperti melakukan pekerjaan ekstra di luar waktu yang telah ditentukan. Standar pekerjaan adalah kesan yang dimiliki oleh individu mengenai pekerjaannya, misalnya perasaan yang timbul mengenai beban kerja yang harus diselesaikan dalam jangka waktu tertentu.

\section{KESIMPULAN}

Berdasarkan hasil penelitian dan pembahasan, maka dapat ditarik kesimpulan sebagai berikut: Hasil penelitian menunjukkan bahwa variabel beban kerja berpengaruh positif terhadap kinerja karyawan di Lingkungan Institut Agama Islam Negeri Palangka Raya. Hal ini dibuktikan dengan hasil statistik uji regresi diperoleh nilai sebesar sebesar ( $\beta$ ) 0.778 (p>0.05; $\mathrm{p}=0,000$ ). Dengan nilai adjust $\mathrm{R}$ square sebesar $34 \%$ dan sebesar $66 \%$ dipengaruhi oleh variabel lain selain variabel beban kerja, maka penelitian ini berhasil menunjukkan bahwa beban kerja memiliki pengaruh posititf dan signifikan terhadap kinerja.

\section{DAFTAR PUSTAKA / REFERENCES}

Moeheriono, Pengukuran Kinerja Berbasis Kompetensi. Bogor: Ghalia, 2009.

Handoko, T. Hani., Manajemen Personalia dan Sumberdaya Manusia, Yogyakarta: BPFE, 2001.

Astianto, Anggit., Pengaruh Stres Kerja dan Beban Kerja Terhadap Kinerja Karyawan PDAM Surabaya. Jurnal Ilmu dan Riset Manajemen Vol. 3 No. 7, 2014. 
Bruggen, Alexander., An Empirical Investigation of The Relationship Between Workload and Performance, Management Decision, Vol. 53 Issue: 10, pp.2377-2389, 2015.

Nitisemito, Alex S., Manajemen Personalia, Jakarta, Penerbit Ghalia Indonesia: 1982

Diartha, I Gusti Ngurah Agung Puspa dan Sudibya, I Gde Adnyana, Moderation Effect of Physical Work Environment in The Effect of Human Resources Placement on Employees Performance in Badung District Government in Indonesia, International Journal of Economics, Commerce and Management, United Kingdom Vol. VI, Issue 9, 2018

Tulangow, Margaritha J., Saerang, David P.E. dan Rumokoy, Farlane S., Analisis Pengaruh Stress Kerja, Lingkungan Kerja dan Beban Kerja Berlebihan Terhadap Keinginan Pergantian Karyawan (Studi Kasus Pt. Wika Realty Manado), Jurnal EMBA Vol.6 No.2, Hal. $474-482,2018$

Danang, Sunyoto., Manajemen Sumber Daya Manusia.Jakarta: PT.Buku Seru, 2012

Gibson, Ivancevich Donelly., Organisasi. Jakarta: Erlangga, 2009

Mangkunegara, Anwar Prabu, Manajemen Sumber Daya Manusia Perusahaan, Bandung: PT Remaja RosdaKarya, 2009

Gomes, Faustino Cardoso., Manajemen Sumber Daya Manusia. Jakarta: Andi Offset, 2003.

Rivai, Veithzal., Manajemen Sumber Daya Manusia Untuk Perusahaan dari Teori ke Praktik, Jakarta: Raja Grafindo Persada, 2009.

Anoraga dan Widiyanti., Psikologi dalam Perusahaan. Jakarta: Rineka Cipta, 1993.

Sedarmayanti., Sumber Daya Manusia dan Produktivitas Kerja, Bandung: Mandar Maju, 2001.

Warr P., Psychology at Work. 5th Ed. England: Penguin Books, 2002.

Gibson, L. James., Donnelly, H. James., dan Ivancevich, John M. Manajemen, Edisi 9. Jilid 2. Jakarta: Erlangga, 1997.

Cooper, D. R. dan Schindler. P.S., Business Research Methods. 11th ed. McGraw Hill International Edition, 2011

Putra, A.S., Analisis Pengaruh Beban Kerja terhadap Kinerja Karyawan Divisi Marketing dan Kredit PT. WOM Finance Cabang Depok. Institut Pertanian Bogor, 2012

Hair, J. F., Black, W. C., Babin, B. J., dan Anderson, R. E. Multivariate data analysis. (7th edition). New Jersey :Pearson Education Inc, 2010.

Neuman, W. L., Social Research Method: Qualitative and Quantitative Approaches, 6th ed. Pearson Education, 2006.

Gudono. Analisis Data Multivariat. Yogyakarta. BPFE, 2014.

Anderson, J. C.,\&Gerbing, D. W., Structural Modeling in Practice: A Review and Recommended Two-Step Approach,Psychological Bulletin, 103 (3), 411-23, 1988. 
Sholihin, M., \& Ratmono, D., Analisis SEM-PLS dengan warpPLS 3.0: untuk hubungan nonlinier dalam penelitian sosial dan bisnis. Yogyakarta, ANDI, 2013. 